\title{
TESTANDO A TEORIA DE HIERARQUIZAÇÃO DE FONTES DE FINANCIAMENTO NAS EMPRESAS BRASILEIRAS*
}

\author{
OTÁVIO RIBEIRO DE MEDEIROS \\ Professor da Universidade de Brasília e do Mestrado Multiinstitucional \\ e Inter-Regional UnB, UFPB, UFPE e UFRN \\ E-mail: otavio@unb.br
}

\section{CECÍLIO ELIAS DAHER}

Professor da Universidade Estadual de Goiás - GO

E-mail: cdaher@bluebottle.com

\section{RESUMO}

O presente trabalho testa se a teoria conhecida como Pecking Order Theory ou Teoria de Hierarquização de Fontes de Financiamento (THFF) fornece explicação empírica para a estrutura de capital das empresas no Brasil. De acordo com essa teoria, a estrutura de capital seria resultante de um funding hierarquizado, em que os recursos gerados internamente teriam prioridade, seguidos pela emissão de dívida e, apenas em último caso, pela emissão de ações. Em sua forma forte, a THFF sustenta que emissões de ações nunca ocorreriam, enquanto, em sua forma fraca, volumes limitados de emissões são aceitáveis. A metodologia do estudo empírico envolve regressões em cross-section e testes de hipóteses para especificações oriundas da teoria em questão para as formas forte e fraca. Os resultados levam a concluir que a teoria testada, em sua forma fraca, é aplicável às empresas brasileiras, o mesmo não ocorrendo com a sua forma forte. Mostram, também, que a qualidade de ajustamento das regressões para o Brasil é significativamente melhor do que aquelas relatadas para empresas norteamericanas e que as empresas brasileiras parecem estar mais próximas da forma forte da THFF do que as norte-americanas. A amostra consiste de 132 empresas de capital aberto e os dados contábeis referem-se a 2001.

Palavras-chave: Estrutura de Capital; Pecking Order; Estudo Empírico; Empresas brasileiras.

\begin{abstract}
The paper tests if the theory known as Pecking Order Theory provides empirical explanations for the capital structure of Brazilian firms. According to this theory, the capital structures would result from a hierarchy of financial decisions, in which internally generated resources would have first priority, followed by debt issues and, as a last resort only, by equity issues. In its strong form, the Pecking Order sustains that equity issues would never occur, whereas in its weak form, limited amounts of issues are acceptable. The methodology adopted in this empirical study involves cross-sectional regressions and the testing of hypotheses based on the underlying theory in its strong and weak forms. The results led to the conclusion that the tested theory, in its weak form, is applicable to Brazilian firms, but that the same does not happen in its strong form. The results also show that the goodness of fit of the Brazilian regressions are significantly better than those reported for American firms and that Brazilian firms seem to be closer to the Pecking Order's strong form than the American ones. The sample involves 132 publicly listed firms and the accounting data refer to 2001.
\end{abstract}

Keywords: Capital Structure; Pecking Order; Empirical Study; Brazilian Firms. 


\section{INTRODUÇÃO}

$\mathrm{Na}$ esteira das seminais contribuições de Modigliani e Miller $(1958,1963)$ à teoria das finanças, inúmeros autores ${ }^{1}$ vêm tentando encontrar os fatores que levam as empresas a estabelecer uma determinada estrutura de capital. Pesquisas empíricas foram feitas em várias frentes, com base em diversas teorias ou hipóteses, tais como a teoria da agência, a hipótese da assimetria das informações ou na questão das decisões estratégicas em relação à concorrência, dentre outras. Ross (1977), por exemplo, adicionou à questão da determinação da estrutura de capital uma nova variável: o custo de falência que se aplica a empresas com elevado endividamento.

Uma das principais teorias em voga, proposta por Myers (1984) e Myers e Majluf (1984), é conhecida na literatura internacional de finanças como Pecking Order Theory ${ }^{2}$, doravante Pecking Order, na qual a estrutura de capital é função de decisões hierárquicas com relação ao funding utilizado pela empresa para cobrir seus investimentos.

O presente trabalho propõe-se a testar empiricamente essa teoria no âmbito de uma amostra de empresas brasileiras de capital aberto. Para tanto, foram utilizados dados obtidos a partir de demonstrações financeiras divulgadas pela Economática ${ }^{\circledR}$. A metodologia utilizada é similar àquela empregada por Shyam-Sunder e Myers (1999) e Frank e Goyal (2003). A amostra envolve dados de 132 empresas para o ano de 2001.

No Brasil, existem diversos estudos ${ }^{3}$ que investigam se as diferentes teorias de estrutura de capital produzem no Brasil os mesmos resultados obtidos em países com economias e mercados mais desenvolvidos, principalmente EUA e alguns países europeus. Porém, com exceção de Daher (2004), tais estudos ou não testam especificamente a THFF no Brasil ou não utilizam metodologia comparável àquela aqui utilizada. Por isso, apenas o estudo de Daher (2004) será aqui comentado, dentro da seção 3.
Os resultados obtidos no presente trabalho são favoráveis à validação da forma fraca da THFF do ponto de vista empírico. Isso confirmaria que, ao financiarem seu déficit de fundos, as empresas recorrem, inicialmente, aos recursos gerados internamente, seguidos pela emissão de dívidas e, apenas em último caso, pela emissão de ações novas. Entretanto, os autores concordam com a crítica de Chirinko e Singha (2000) de que os modelos testados atestam que a hierarquia da THFF é válida em termos das quantidades e não do timing das diferentes formas de financiamento. A forma forte da THFF não foi empiricamente validada no estudo atual.

O restante do trabalho está composto da seguinte maneira. Na seção 2, é apresentada uma revisão sobre a teoria em questão. $\mathrm{Na}$ seção 3 , são discutidos alguns resultados empíricos anteriores. Na seção 4, estão descritos os dados, os métodos utilizados e os resultados esperados. A seção 5 analisa os resultados obtidos, a seção 6 apresenta as conclusões e a seção 7 descreve as referências.

\section{TEORIA}

Myers (1984) divide o pensamento atual sobre a determinação da estrutura de capital das empresas em duas correntes. A primeira denomina-se Static Tradeoff Theory ${ }^{4}$, na qual se supõe que a empresa estabelece uma meta de endividamento e procura atingí-la ao longo do tempo. Embora a empresa possa se afastar da meta no curto prazo, o objetivo é mantido no longo prazo, mesmo que, na prática, possa nunca ser de fato atingido. A segunda corrente, proposta pelo próprio Myers (1984) e Myers e Majluf (1984), é a Pecking Order.

Em linhas gerais, a THFF diz que as empresas obedeceriam a uma hierarquia, quando da busca por funding para financiar seus projetos, recorrendo inicialmente a recursos gerados internamente, seguidos pela emissão de dívida ${ }^{5}$ e, finalmente, pela emissão de ações novas. A idéia é que a emissão

\footnotetext{
${ }^{1}$ Dentre esses autores pode-se citar Ross (1977), Myers (1984 e 1977), Myers e Majluf (1984), Marsh (1982), dentre vários outros. Numa ampla pesquisa sobre o tema, Harris e Raviv (1991), analisam vários trabalhos realizados com diferentes abordagens.

${ }^{2}$ Literalmente, "ordem da bicada", referindo-se à hierarquia social existente entre algumas espécies de aves, na qual cada ave tem o direito de bicar aquelas subordinadas e se submete a ser bicado pelas aves dominantes. Nesse texto será utilizada a expressão correspondente em português: Teoria de Hierarquização de Fontes de Financiamento ou, abreviadamente, THFF.

${ }^{3}$ Famá e Grava (2000), Famá et al. (2001), Famá e Melher (1999), Kayo e Famá (1997) e Daher (2004) estudaram a aplicabilidade de várias teorias existentes para Brasil, com diferentes metodologias.

${ }^{4}$ Literalmente, "teoria do balanceamento estático", na tradução livre dos autores.

${ }^{5}$ O termo "emissão de dívida" é aqui empregado em sentido amplo, isto é, não somente através de emissão de debêntures, mas incluindo, por exemplo, empréstimos e financiamentos não securitizados do BNDES, FINAME ou equivalentes.
} 
de ações novas seja realizada muito raramente ou como último recurso. A ordem hierárquica é fundamental para a teoria. Caso a emissão de novas ações seja considerada em primeiro lugar pelas empresas, mesmo que essas sejam emitidas em proporções mínimas, a THFF não se sustenta.

O pano de fundo para a existência dessa hierarquia é a assimetria de informações entre os gestores e os novos potenciais acionistas. Essa assimetria levaria a empresa à destruição de valor para os acionistas atuais caso decidisse pela nova emissão, já que a implantação de novos projetos poderia não ser corretamente avaliada pelo mercado, acarretando uma subavaliação das novas ações e a conseqüente transferência de riqueza dos acionistas antigos para os novos. Para Myers (1984) e Myers e Majluf (1984), a THFF implica, ainda, que as empresas mais lucrativas seriam naturalmente menos endividadas, já que elas financiariam seus projetos novos sem se endividar ou sem emitir ações novas.

Em sua forma mais simples, o modelo associado à THFF sustenta que, quando o fluxo de caixa interno da empresa é inadequado para cobrir os investimentos e os compromissos de pagamento de dividendos, a empresa emite dívida. Ações nunca são emitidas, exceto quando a única alternativa é emitir dívida de alto risco (junk debt) ou quando os custos de falência são elevados. Para descrever o modelo representativo da Pecking Order, as definições abaixo são necessárias:

$C_{t} \quad=$ fluxo de caixa operacional após juros e impostos;

$D I V_{t}=$ pagamento de dividendos;

$I_{t} \quad=$ investimentos de capital;

$\Delta W_{t}=$ aumento líquido do capital de giro,

$D_{t} \quad=$ dívida exigível de longo prazo,

em que todas as variáveis são mensuradas ao final do período $t$. O déficit de fundos é dado pela seguinte identidade contábil:

$$
D E F_{t} \equiv D I V_{t}+I_{t}+\Delta W_{t}-C_{t} .
$$

A THFF considera que todos os componentes do déficit são exógenos, desde que dívidas saudáveis (sem risco, isto é, excluídas as junk bonds) possam ser emitidas. É importante enfatizar que a equação (1) implica a independência da política de dividendos de volume de investimentos. Essa premissa está de acordo com Modigliani e Miller (1961), segundo os quais a decisão de dividendos é independente da decisão de investimentos.

Para fins de avaliação empírica, todas as variáveis acima definidas são divididas pelo ativo total, de modo a suprimir o efeito tamanho e reduzir o problema da heteroscedasticidade, isto é, de uma variância não constante ao longo de uma amostra que envolve empresas de porte muito diverso.

A hipótese da THFF pode ser testada empiricamente em cross-section através da equação linear

$$
\Delta D_{i}=\alpha+\beta D E F_{i}+u_{i}
$$

na qual $\alpha$ é um intercepto, $\beta$ a inclinação da reta, $\Delta D_{i}$ é a variação do montante de dívida emitida pela $i$-ésima empresa, DEF é o déficit financeiro da $i$-ésima empresa e $u_{i}$ é um termo aleatório i.i.d. $\mathrm{N}\left(0, \sigma^{2}\right)$.

Na forma forte da THFF, espera-se que $\alpha=0$ e $\beta=1$, pois isso significaria que a emissão de dívida é diretamente proporcional ao déficit de fundos, não havendo, portanto, espaço para a emissão de ações. A equação (2) não é uma identidade contábil porque $D E F_{i}$ não inclui emissões ou recompra de ações. $\mathrm{A}$ THFF prevê que a empresa só emitirá ou recomprará ações como último recurso. A hipótese de que os componentes do déficit são exógenos permite que a estimação de (2) seja feita por mínimos quadrados ordinários (OLS) sem que os parâmetros estimados sejam enviesados e inconsistentes.

Por outro lado, a forma fraca da THFF admite um certo nível de emissão de ações, sendo considerado por Chirinko e Singha (2000) como mais plausível e provável de ser encontrada e testada. Aqui, o coeficiente $\beta$ seria menor que um, mas próximo a esse valor. Nesse caso, não há uma hipótese nula muito precisa e a constante a poderia ser diferente de zero, sem invalidar o modelo (CHIRINKO e SINGHA, 2000).

Em resumo, testar, empiricamente, a validade da THFF em sua forma forte significa testar $\mathrm{H}_{0}: \alpha=$ 0 e $\beta=1$, enquanto, na forma fraca, significa testar se $\beta<1$, porém próximo de 1 (por exemplo, $H_{0}: \beta$ $=0,8)$. A rejeição de $H_{0}$, na forma forte e na forma fraca, implica na rejeição da THFF.

\section{EVIDÊNCIAS}

Diversas evidências empíricas sobre a THFF estão disponíveis na literatura. $\mathrm{Na}$ interpretação de Shyam-Sunder e Myers (1999), a THFF é uma explicação muito melhor da escolha entre capital de terceiros $x$ capital próprio, pelo menos no que se refere a empresas abertas e maduras, do que a teoria da escolha estática, embora reconheçam que a THFF simples não explica tudo.

No teste empírico da THFF, Shyam-Sunder e Myers (1999) encontraram, para uma amostra de 157 empresas, $\alpha=0,002$ e $\beta=0,75$, com erros padrões 
de 0,0009 e 0,01, respectivamente, mostrando que $\alpha$ não é, significativamente, diferente de zero e $\beta$ não é, significativamente, diferente de 0,75 , ambos ao nível de $1 \%$. O coeficiente $R^{2}$ encontrado foi de 0,68 . Esse resultado valida a THFF em sua forma fraca, pois se $\beta \approx 0,75$, é porque ocorreram algumas emissões de ações, porém muito abaixo das emissões de dívida. Outros testes foram relatados no artigo em pauta, mas por não se referirem à THFF pura e sim a diferentes especificações dela, não são comparáveis ao presente trabalho. Há outros estudos empíricos sobre a Pecking Order, tais como Adedeji (2002), com resultados similares aos aqui relatados.

É importante mencionar que Shyam-Sunder e Myers (1999) consideram na definição de $D E F$ a dívida de longo prazo em sua totalidade, enquanto Frank e Goyal (2003) testam duas versões. Em uma delas, não incluem na definição de $D E F$ a parcela corrente da dívida de longo prazo e, na outra, incluem-na. Segundo os autores, o resultado empírico indica que a parcela corrente da dívida de longo prazo parece não se ajustar bem à definição de $D E F$. A não inclusão da parcela corrente da dívida de longo prazo favorece a Pecking Order, mas isso não altera as conclusões daquele trabalho.

Outra diferença entre o teste da THFF feito por Frank e Goyal (2003) e o de Shyam-Sunder e Myers (1999) foi o agrupamento por tamanho das empresas, definido pelo valor contábil dos ativos, enquanto Shyam-Sunder e Myers (1999) estimaram sua equação para todo o grupo, sem distinção de tamanho, encontrando um resultado bastante interessante. A THFF pressupõe que empresas com maiores assimetrias de informação, tais como as pequenas e aquelas com crescimento rápido, se ajustariam melhor à teoria. O resultado encontrado por Frank e Goyal (2003) foi exatamente o oposto. As maiores empresas foram as que mais se ajustaram à THFF, principalmente no primeiro período considerado, fato que foi diminuindo com o passar dos anos. O motivo apontado pelos autores foi o maior interesse pela emissão de ações nos anos 90 e a entrada de muitas pequenas empresas no mercado. Com uma amostra de 14.592 observações, o resultado de Frank e Goyal (2003) para a amostra total, sem distinção de tamanho, apresentou $\alpha=0,001$ e $\beta$ $=0,748$, com erros padrões de 0,001 e 0,004, fazendo com que $\alpha$ não seja significativamente diferente de zero e $\beta$ não seja significativamente diferente de 0,75 , ambos ao nível de 0,01 . $O R^{2}$ relatado foi de 0,708 . Tais resultados, também, dão sustentação à THFF em sua forma fraca. Apesar desses resultados, outros testes levaram Frank e Goyal (2003) a afirmar que, ao contrário do previsto pela THFF, a emissão de ações explica o déficit de fundos com maior aproximação do que a emissão de dívida. Relatam, ainda, que, embora as grandes empresas apresentem alguns aspectos da THFF, a evidência não é robusta quando são incluídos na equação variáveis convencionais associadas à alavancagem.

Críticas foram feitas por Chirinko e Singha (2000) ao modelo testado por Shyam-Sunder e Myers (1999) e aos resultados por eles encontrados que favorecem a THFF. Os primeiros mostram, por exemplo, que a emissão de ações poderia ter sido feita antes da emissão de novas dívidas, mesmo que em proporções menores que essas. Nesse caso, apesar de a ordem hierárquica da THFF ter sido violada, o resultado empírico levaria à sua aceitação, simplesmente porque o coeficiente $\beta$ seria próximo de 1, já que o volume de emissões de ações foi pequeno. Em outras palavras, a crítica de Chirinko e Singha (2000) é de que os testes empíricos de Shyam-Sunder e Myers (1999) indicam que, mesmo que a emissão de ações seja realizada em menores volumes do que as outras formas de funding, isto é, geração interna de caixa e dívida, isso não significa que a emissão de ações tenha ocorrido por último. Assim, a hierarquia da THFF não seria temporal, mas sim por volume.

Recentemente, Daher (2004) realizou estudo testando no Brasil não apenas a THFF, mas também a Static Tradeoff Theory, confrontando-as empiricamente. $O$ estudo é robusto e utiliza regressões com dados em painel (panel data) com modelos de efeitos fixos e aleatórios, com uma amostra de 420 empresas entre 1995 e 2002. As principais conclusões de Daher (2004) são as de que a THFF, em sua forma forte, é a teoria que melhor explica a estrutura de capital das empresas brasileiras.

\section{MÉTODOS}

O estudo empírico ora relatado utilizou uma amostra composta de dados de 132 empresas não-financeiras listadas em Bolsa no ano de 2001, extraídas da base de dados da Economática ${ }^{\circledR}$, tendo-se excluído as instituições financeiras, por terem características diferenciadas, com demonstrações contábeis e planos de contas bastante diversos das empresas dos demais setores. As 132 empresas remanescentes da amostra resultaram de uma amostra inicial de 420 empresas listadas na BOVESPA e na SOMA, tendo-se excluído, além das instituições financeiras, aquelas empresas com dados incompletos nas demonstrações financeiras de 2000 ou de 2001 e aquelas que, nesses anos, tenham passado por processos de fusão, aquisição, incorporação, privatização, concordata ou falência. A eliminação das empresas com dados faltantes, também, em 2000 
deve-se ao fato de que as variáveis utilizadas nas regressões estão em diferenças e não em níveis.

A amostra é transversal, ou seja, todas os dados para as variáveis referem-se a várias empresas numa única data, o que é conhecido como crosssection data. De modo a padronizar as variáveis, procurando minimizar o efeito tamanho, bem como reduzir problemas de heteroscedasticidade, em função da existência de valores contábeis muito discrepantes, todas as variáveis contábeis utilizadas no estudo foram divididas pelos ativos totais das respectivas empresas, tal como em ShyamSunder e Myers (1999) e Frank e Goyal (2003).

O método utilizado é o de regressão linear (OLS) em cross-section. Duas equações alternativas foram testadas. Primeiramente, foi testada uma especificação econométrica tendo como variável independente o déficit agregado, isto é,

$$
\Delta D_{i}=\alpha+\beta D E F_{i}+u_{i},
$$

em que $\Delta$ é o operador de diferença de 1a. ordem, $D_{i}$ o endividamento líquido e DEF o déficit de fundos, dado pela identidade contábil

$$
D E F_{i} \equiv I_{i}+\Delta W_{i}+D I V_{i}-C_{i},
$$

em que $/$ é o investimento líquido em ativo fixo, $W$ o capital circulante líquido, DIV os dividendos pagos e $C$ é o caixa gerado após juros e impostos. O subscrito $t$ refere-se ao período de tempo e o subscrito $i$ refere-se a $i$-ésima empresa.

As variáveis incluídas nas equações (3) e (4) foram obtidas da seguinte forma, a partir da demonstração de origens e aplicações das empresas da amostra, disponíveis na base de dados da Economática ${ }^{\circledR}$ :

$\Delta D=$ Aumento do Passivo de LP - Transferências do Exigível de LP para o Circulante + Financiamentos e Debêntures + Outras Origens - Diminuição do Passivo de LP + Transferência do Circulante para o Exigível de LP;

$D I V$ = Dividendos;

$I=$ Aumento no Investimento Permanente + Compra de Ativos Fixos + Aumentos do Diferido + Aumento do Realizável de LP + Controladas + Incorporações + Participações Minoritárias + Outros Recursos Aplicados - Venda de Ativos Fixos - Venda de Bens do Permanente - Redução do Realizável a LP;
$\Delta W=$ Aumento do Capital Circulante Liquido;

$C=$ Total de Recursos Obtidos nas Operações - Venda de Ativo Fixo + Dividendos Recebidos + Incentivos Fiscais + Capital Circulante Incorporado de Controladas.

Ao se estimar a equação (3), espera-se, na forma forte da THFF, $\alpha=0$ e $\beta=1$, enquanto, na forma fraca, $\alpha$ pode ser diferente de zero e $\beta$ deve ser próximo de 1 , mas menor que 1. Não foi incluída, no lado direito da equação (4) a parcela de curto prazo da dívida de longo prazo, como em Shyam-Sunder e Myers (1999).

Testou-se, também, uma especificação alternativa, utilizada em Frank e Goyal (2003), em que as variáveis que compõem o déficit estão desagregadas, ou seja, substituindo DEF na equação (3) pela sua expressão dada pela equação (4), ou seja,

$$
\Delta D_{i}=\alpha+\beta_{1} I_{i}+\beta_{2} \Delta W_{i}+\beta_{3} D I V_{i}+\beta_{4} C_{i}+u_{i}
$$

Na estimação da equação (5), é de se esperar que na forma forte da THFF se obtenha $\alpha=0$, que $\beta_{1}, \beta_{2}, \beta_{3}$ sejam iguais a 1 e $\beta_{4}=-1$. Na forma fraca da teoria, $\alpha$ pode ser diferente de zero, $\beta_{1}, \beta_{2}$ e $\beta_{3}$ devem ser menores que, mas próximos de 1 , e $\beta_{4}$ deve ser maior que, mas próximo de -1 .

Um ponto importante é a exogeneidade de $D E F$ na equação (3) e dos seus componentes na equação (5). Na teoria original de Myers (1984), bem como nos estudos empíricos de Shyam-Sunder e Myers (1999) e Frank e Goyal (2003), DEF é considerada exógena, desde que a empresa esteja apta a emitir dívida saudável, isto é, exclusive junk debt. Isso significa que a curva de oferta de crédito à empresa seria horizontal, ou seja, seria possível à empresa emitir dívida sem aumentos progressivos dos juros. Assim, não haveria feedback entre $D E F$ e a variação do endividamento líquido $\Delta \mathrm{D}$. Caso contrário, ocorreria um viés de simultaneidade, em que $D E F$ seria correlacionada com $u$, e a equação teria que ser estimada por outros métodos, tais como variáveis instrumentais (IV), mínimos quadrados em dois estágios (TSLS) ou máxima verossimilhança com informação limitada (LIML) $)^{6}$, de modo a evitar o viés de simultaneidade, o que faria com que os parâmetros estimados fossem enviesados e inconsistentes. No presente trabalho, assumiu-se como válida a hipótese de exogeneidade de $D E F$ e de seus componentes.

Convém ressaltar ainda que não é necessário eliminar da amostra os casos em que $\mathrm{DEF}<0$, isto

\footnotetext{
${ }^{6}$ Vide Greene (2003).
} 
é, aqueles em que a empresa tem um superávit financeiro ao invés de déficit, uma vez que as equações (3) e (5) continuam válidas, e a contrapartida será uma redução no endividamento, isto é, $\Delta \mathrm{D}<$ 0 . Esse procedimento está de acordo com aquele adotado por Shyam-Sunder e Myers (1999) e Frank e Goyal (2003).

A metodologia empregada no presente trabaIho incluiu, também, uma série de testes de diagnósticos sobre os dados referentes às variáveis $e$ sobre os resíduos das regressões, de modo a garantir a robustez do estudo. Os testes dos resíduos das equações (3) e (5) foram os de White (1980) para a presença de heteroscedasticidade, o de Bera e
Jarque (1981) para normalidade e ainda o teste $F$ para a existência de regressão.

\section{RESULTADOS}

O Quadro 1 mostra as estatísticas descritivas das variáveis utilizadas, incluindo os resultados do teste de Bera-Jarque e as probabilidades ( $p$-values) correspondentes, que revelam a não-normalidade de todas as variáveis contábeis. Conforme já mencionado, todas as variáveis contábeis foram divididas pelos ativos totais das respectivas empresas, de modo a minimizar o efeito tamanho e a ocorrência de heteroscedasticidade.

\begin{tabular}{l|c|c|c|c|c}
\hline & $\mathbf{C}$ & $\Delta \mathbf{D}$ & $\mathbf{D I V}$ & $\Delta \mathbf{W}$ & $\mathbf{I}$ \\
Média & 0,140519 & 0,018287 & 0,018342 & 0,075123 & 0,081558 \\
\hline Mediana & 0,068014 & 0,000000 & 0,000000 & $-0,001490$ & 0,057033 \\
\hline Máximo & 9,295866 & 0,891042 & 0,274483 & 9,732558 & 0,731207 \\
\hline Mínimo & $-0,824383$ & $-0,557681$ & 0,000000 & $-1,105951$ & $-0,621447$ \\
\hline D. Padrão & 0,835637 & 0,165042 & 0,034798 & 0,884949 & 0,167600 \\
\hline Assimetria & 10,12425 & 1,708192 & 3,794414 & 9,974362 & 0,521177 \\
\hline Curtose & 111,0122 & 12,42078 & 24,50683 & 109,1862 & 6,740806 \\
\hline Bera-Jarque & 66421,49 & 552,3255 & 2860,738 & 64204,08 & 82,94070 \\
\hline Probabilidade & 0,000000 & 0,000000 & 0,000000 & 0,000000 & 0,000000 \\
\hline Observações & 132 & 132 & 132 & 132 & 132
\end{tabular}

Fonte: Elaborado pelos autores.

\section{Quadro 1 - Estatísticas Descritivas das Variáveis Utilizadas}

Os resultados obtidos para a equação (3) estão apresentados no Quadro 2, juntamente com aqueles relatados por Shyam-Sunder e Myers (1999) e Frank e Goyal (2003).

O Quadro 2 mostra os valores dos coeficientes estimados, o $R^{2}$ das regressões, os erros padrões (SE) dos coeficientes, as estatísticas t para a significância de $\alpha$ e $\beta$ e para $\beta=1$ e o intervalo de confiança para $\beta$. Verifica-se que a hipótese $H_{0}: \alpha$ $=0$ é aceita, mas $\mathrm{H}_{0}: \beta=1$ é rejeitada, ambas ao nível de $5 \%$, contrariando a expectativa da versão forte da THFF. O intervalo de confiança não inclui o valor 1. Porém, $H_{0}: \beta=0,9$ é aceita ao nível de $5 \%$, pois 0,9 está dentro do intervalo de confiança, validando a versão fraca da THFF. Esses resultados são similares aos de Shyam-Sunder e Myers (1999) e de Frank e Goyal (2002), sendo que, para ambos, um $\beta$ de 0,75 , menor, portanto, que o do presente estudo, foi encontrado. Nessa equação, as evidências apontam, portanto, para a aceitação da THFF

\begin{tabular}{l|c|c|c|c|c} 
Coef. & Valor & SE & $\begin{array}{c}\mathbf{t} \\
\left(\mathbf{H}_{0}: \alpha, \beta=\mathbf{0}\right)\end{array}$ & $\begin{array}{c}\mathbf{t} \\
\left(\mathbf{H}_{0}: \beta=\mathbf{1}\right)\end{array}$ & $\begin{array}{c}\text { Intervalo } \\
\text { confiança } \\
95 \%\end{array}$ \\
\hline$\alpha$ & $-0,011$ & 0,006 & $-1,693$ & & \\
\hline$\beta$ & 0,86 & 0,038 & 22,172 & $-3,68$ & $0,78-0,93$ \\
\hline$R^{2}$ & 0,791 & & & & \\
\hline \multicolumn{6}{|l}{ Shyam-Sunder e Myers (1999) } \\
\hline$\alpha$ & 0,002 & 0,0009 & 2,22 & & \\
\hline$\beta$ & 0,75 & 0,01 & 75,00 & $-25,00$ & $0,73-0,77$ \\
\hline$R^{2}$ & 0,21 & & & & \\
\hline Frank e Goyal (2003) & & & & \\
\hline$\alpha$ & 0,001 & 0,0005 & 2,00 & & \\
\hline$\beta$ & 0,748 & 0,004 & 187,00 & $-63,00$ & $0,74-0,76$ \\
\hline$R^{2}$ & 0,678 & & & & \\
\hline
\end{tabular}

Fonte: Elaborado pelos autores.

Quadro 2 - Déficit agregado 
na forma fraca, tal como em Shyam-Sunder e Myers (1999) e Frank e Goyal (2003).

O Quadro 3 mostra os resultados da equação (5), isto é, com o déficit na forma desagregada e os resultados correspondentes de Frank e Goyal (2003). A hipótese $H_{0}: \alpha=0$ é aceita. A hipótese $H_{0}$ : $\beta=1$ só é aceita para $\beta_{3}$. Para todos os demais $\beta$ os valores aceitos são próximos, mas menores do que 1, em valor absoluto. Assim, pode-se afirmar, novamente, que a forma forte da THFF é rejeitada, mas em sua forma fraca ela é aceita. Em Frank e Goyal (2003), $H_{0}: \alpha=0$ é aceita e as demais $H_{0}$ são aceitas em valor absoluto para valores entre $0,73 \mathrm{e}$ 0,85 , levando, também, à rejeição da forma forte e à aceitação da forma fraca.

\begin{tabular}{l|c|c|c|c|c} 
Coef. & Valor & SE & $\begin{array}{c}\mathbf{t} \\
\left(\mathbf{H}_{0}: \alpha, \beta=0\right)\end{array}$ & $\begin{array}{c}\mathbf{t} \\
\left(\mathbf{H}_{0}: \beta=1\right)\end{array}$ & $\begin{array}{c}\text { Intervalo } \\
\text { confiança } \\
95 \%\end{array}$ \\
$\alpha$ & $-0,0009$ & 0,007 & $-0,118$ & & \\
\hline$\beta 1(\mathrm{I})$ & 0,75 & 0,047 & 15,688 & $-5,32$ & $0,66-0,84$ \\
\hline$\beta 2(\Delta \mathrm{W})$ & 0,902 & 0,039 & 22,925 & $-2,51$ & $0,83-0,98$ \\
\hline$\beta 3(\mathrm{DIV})$ & 0,997 & 0,191 & 5,2139 & $-0,02$ & $0,62-1,37$ \\
\hline$\beta 4(\mathrm{C})$ & $-0,911$ & 0,039 & $-22,813$ & $-2,28$ & $-0,83--0,99$ \\
\hline $\mathrm{R}^{2}$ & 0,811 & & & & \\
\hline Frank e Goyal (2003) & & & \\
\hline$\alpha$ & $-0,006$ & 0,001 & $-6,00$ & & \\
\hline$\beta 1(\mathrm{I})$ & 0,774 & 0,005 & 154,80 & $-45,20$ & $0,76-0,78$ \\
\hline$\beta 2(\Delta \mathrm{W})$ & 0,723 & 0,005 & 144,60 & $-55,40$ & $0,71-0,73$ \\
\hline$\beta 3(\mathrm{DIV})$ & 0,884 & 0,02 & 44,20 & $-5,80$ & $0,84-0,92$ \\
\hline$\beta 4(\mathrm{C})$ & $-0,739$ & 0,005 & $-147,80$ & $-52,20$ & $-0,73--0,75$ \\
\hline$R^{2}$ & 0,695 & & & & \\
\hline
\end{tabular}

Fonte: Elaborado pelos autores.

\section{Quadro 3 - Déficit desagregado}

Ressalte-se que os $\mathrm{R}^{2}$ obtidos no presente trabalho, tanto na forma agregada quanto na desagregada, são mais elevados que aqueles obtidos pelos autores estrangeiros. Além disso, embora os resultados do presente estudo tenham levado à aceitação da THFF em sua forma fraca, tal como em Shyam-Sunder e Myers (1999) e Frank e Goyal (2003), os valores dos $\beta$ são mais elevados no estudo atual do que naqueles, indicando que as empresas brasileiras parecem estar mais próximas da forma forte da THFF do que as empresas norteamericanas.

O resultado dos testes de diagnóstico das regressões está mostrado no Quadro 4. As estatísticas e probabilidades ( $p$-values) associadas não mostram evidências de autocorrelação e heteroscedasticidade nos resíduos. O teste $\mathrm{F}$ comprova a validade das relações entre as variáveis. $O$ ponto negativo é que não é possível aceitar a hipótese $\mathrm{H}_{0}$ de que os resíduos são normalmente distribuídos, conforme necessário para a validade dos testes $t$ sob OLS. Felizmente, tendo em vista que a amostra é suficientemente grande $(n=132)$, a violação da normalidade é virtualmente inconseqüente, dado o Teorema do Limite Central. ${ }^{7}$ A conclusão é que os testes de diagnóstico das regressões permitem sustentar a robustez da análise.

Os resultados estatísticos obtidos para ambas as equações testadas levam a aceitar que a THFF, em sua forma fraca, é aplicável às empresas brasileiras listadas em Bolsa em 2001, excluídas da amostra as empresas financeiras.

\begin{tabular}{c|c|c|c|c|c|c}
\hline & \multicolumn{2}{|c|}{ Bera-Jarque } & \multicolumn{2}{c}{ White } & \multicolumn{2}{c}{ F } \\
\cline { 2 - 7 } & Estat. & $\mathbf{p}$ & Estat. & Estat. & p \\
\hline Equação (3) & 8339,22 & 0,0000 & 32,75 & 0,0000 & 491,62 & 0,0000 \\
\hline Equação (5) & 4948,29 & 0,0000 & 66,84 & 0,0000 & 136,33 & 0,0000 \\
\hline
\end{tabular}

Fonte: Elaborado pelos autores.

Quadro 4 - Resultados dos testes de diagnósticos (estatísticas e p-values) 


\section{CONCLUSÕES}

O presente trabalho teve o propósito de contribuir com a busca dos fatores determinantes da estrutura de capital das empresas, ainda uma das grandes incógnitas da moderna teoria das finanças corporativas. Dentre as diversas teorias levantadas nas ultimas décadas, a Teoria de Hierarquização de Fontes de Financiamento (Pecking Order Theory), proposta inicialmente por Myers (1984), sustenta que a estrutura de capital das empresas decorreria de um processo de funding hierarquizado, no qual as empresas obedeceriam a uma hierarquia com relação à utilização ou captação de recursos: os fundos gerados internamente estariam no topo das preferências, seguidos da emissão de debêntures e finalmente da emissão de ações como último recurso. A lógica de tal procedimento estaria principalmente no fenômeno de seleção adversa causado pela relutância dos administradores das empresas em transferir valor dos acionistas antigos para os novos.

Com base nos artigos de Shyam-Sunder e Myers (1999) e Frank e Goyal (2003), procurou-se testar se o funding hierarquizado associado à THFF é observável no Brasil com dados de 2001. Tendo como base as demonstrações contábeis disponíveis na Economática ${ }^{\circledR}$, submeteu-se uma amostra de 132 empresas listadas em bolsa, a duas especificações alternativas que foram estimadas por OLS em cross-section, podendo-se concluir que, durante aquele ano em questão, há indícios de que a teoria em pauta, em sua forma fraca, é aplicável. Os resultados obtidos são semelhantes e comparáveis àqueles relatados em Shyam-Sunder e Myers (1999) e Frank e Goyal (2003).

No entanto, os autores concordam com a crítica de Chirinko e Singha (2000) de que os modelos propostos para avaliar a THFF não têm a capacidade de verificar se a hierarquia da THFF é obedecida em termos do timing das emissões, mas apenas em termos dos volumes das emissões. Em outras palavras, os modelos podem mostrar que os volumes de emissões de ações são bem menores do que os das outras formas de funding, mas não podem revelar qual foi a seqüência temporal adotada pelas empresas.

Os resultados estatísticos obtidos são robustos e podem ser comparados aos de Shyam-Sunder e Myers (1999) e Frank e Goyal (2003) para empresas norte-americanas. Entretanto, ao se compararem os resultados, surgem duas particularidades dignas de nota. Em primeiro lugar, as regressões do presente trabalho apresentam maior poder explanatório, em termos de $\mathrm{R}^{2}$, do que aquelas relatadas naqueles estudos, realizados com empresas norte-americanas, o que poderia significar que a THFF se ajusta melhor ainda às empresas brasileiras do que àquelas.

Em segundo lugar, embora tanto o presente trabalho quanto os de Shyam-Sunder e Myers (1999) e Frank e Goyal (2003) tenham aceitado a THFF apenas em sua forma fraca, o presente trabalho revelou coeficientes $\beta$ relativamente mais próximos da unidade, parecendo indicar que as empresas brasileiras estão mais próximas da forma forte daquela teoria do que as norte-americanas. Essa hipótese parece plausível, se forem levados em conta, por um lado, o ainda relativamente limitado mercado acionário brasileiro, com sua excessiva concentração, baixa liquidez e as conseqüentes dificuldades de captação de recursos via emissão de ações e, por outro, a existência de um banco de fomento estatal com juros de longo prazo subsidiados. Isso poderia ser visto como uma THFF induzida pelo governo, uma vez que é bem mais fácil e viável para as grandes empresas brasileiras levantar recursos de longo prazo no BNDES do que emitir ações.

É importante ressaltar, entretanto, que o fato de o mercado de ações brasileiro ser ainda caracterizado por uma série de limitações, que afetam as empresas participantes, não significa que existam facilidades do lado da oferta de crédito para as empresas. As elevadíssimas taxas de juros reais, vigentes há muitas décadas, resultado de políticas monetárias restritivas, tornam o crédito de curto prazo praticamente proibitivo para as empresas, especialmente para aquelas de pequeno e médio portes, em geral menos capitalizadas. Quanto ao crédito de longo prazo, embora subsidiado pelo governo, através da TJLP (Taxa de Juros de Longo Prazo) praticada pelo BNDES, pode-se dizer que ele é bastante escasso e, ainda que tenha menor custo financeiro que o de curto prazo, é ainda bastante elevado para os padrões internacionais.

A conclusão final é que, colocando na balança, de um lado, as dificuldades de obtenção de crédito no País e, do outro, as dificuldades de captação de recursos via mercado de ações, a preferência das empresas brasileiras recai sobre o endividamento, o que faz com que a Teoria da Hierarquização de Fontes de Financiamento seja aplicável às empresas brasileiras. 


\section{REFERÊNCIAS BIBLIOGRÁFICAS}

ADEDEJI, A., A Cross-sectional Test of Pecking Order Hypothesis against Static Trade-off Theory on UK data, SSRN Working Paper Series, 2002. Disponível em <http://papers.ssrn.com/ sol3/delivery.cfm/SSRN_ID302827_code020312510.pdf?abstrac tid=302827 $>$, acesso em 15.10. 2003.

BERA, A.K.; JARQUE, C.M., An Efficient Large-Sample Test for Normality of Observations and Regression Residuals, Australian National University Working Papers in Econometrics 40, Canberra, 1981.

BROOKS, C.. Introductory Econometrics for Finance. Cambridge, UK: Cambridge U. Press, 2002.

CHIRINKO, R.S.; SINGHA, A.R.. Testing static tradeoff against pecking order models of capital structure: a critical comment. Journal of Financial Economics, vol. 58, p.417-25, 2000.

DAHER, C.. Testes Empíricos de Teorias Alternativas sobre a Determinação da Estrutura de Capital das Empresas Brasileiras. 2004. Dissertação (Mestrado em Ciências Contábeis) - Programa Multiinstitucional e Inter-Regional UnB, UFPB, UFPE, UFRN, Brasília, DF.

FAMÁ, R.; GRAVA, J.W.. Teoria da Estrutura de Capital - As Discussões Persistem, Caderno de Pesquisas em Administração, São Paulo, vol.1, n.11, p.27-36, 2000.

MELHER, S.. Estrutura de Capital na América Latina: Existiria uma Correlação com o Lucro das Empresas? Trabalho apresentado no IV SemeAd, out. 1999.

BARROS, L.; SILVEIRA, A.. A Estrutura de Capital é Relevante? Novas Evidências a Partir de Dados NorteAmericanos e Latino-Americanos. Caderno de Pesquisas em Administração, São Paulo, vol.8, n.2 (abr-jul), p.71-84, 2001.

FRANK, M.Z.; GOYAL, V.K.. Testing the pecking order theory of capital structure. Journal of Financial Economics, vol. 67, p.21748, 2003.
GREENE, W.. Econometric Analysis, $5^{\text {th }}$ ed., Upper Saddle River, NJ: Prentice Hall, 2003.

HARRIS, M.; RAVIV, A. The Theory of Capital Structure. The Journal of Finance, v.46, n.1, p. 297-355, nov. 1978.

KAYO, E. K.; FAMÁ, R.. Teoria da Agência e Crescimento: Evidências Empíricas dos Efeitos Positivos e Negativos do Endividamento, Caderno de Pesquisas em Administração, São Paulo, vol.2, n.5 (2.Sem), p.1-8, 1997.

MODIGLIANI, F.; MILLER, M.. The Cost of Capital, Corporation Finance and the Theory of Investment, The American Economic Review, vol. 48, issue 3 (jun.), p.261-97, 1958.

Dividend Policy, Growth, and the Valuation of Shares, Journal of Business 34, october 1961, p.411-33.

Corporate Income Taxes and the Cost of Capital: A Correction, The American Economic Review, vol. 53, issue 3 (jun.), p.433-43, 1963.

MYERS, S.; MAJLUF, N.. Corporate Financing and Investment Decisions When Firms Have Information that do not Have, Journal of Financial Economics, vol. 13, p.187-221, 1984.

MYERS, S.. The Capital Structure Puzzle, Journal of Finance, vol. 39, n.3 (jul), p.575-92, 1984.

ROSS, S.. The Determination of Financial Structure: the Incentive Signaling Approach, Bell Journal of Economics, vol. 8, p.23-40, 1977.

SHYAM-SANDER, L.; MYERS, S.C.. Testing static tradeoff against pecking order models of capital structure. Journal of Financial Economics, vol. 51, p.219-44, 1999.

WHITE, H., A Heteroskedasticity-Consistent Covariance Matrix Estimator and a Direct Test for Heteroskedasticity, Econometrica 48, p.817-38, 1980.

NOTA:

Dados dos autores:

Otávio Ribeiro de Medeiros

Universidade de Brasília

S/N, ASA NORTE

BRASÍLIA - DF

70910-900
Cecílio Elias Daher

Universidade Estadual de Goiás

Campus BR 153, Km 98

Anápolis - GO

75001-970 